\title{
ASPECTOS DE LA BIOLOGÍA POBLACIONAL EN EL CAMPO DE Anolis aquaticus, Sauria: Polychridae EN COSTA RICA
}

\section{FIELD POPULATION BIOLOGY OF Anolis aquaticus, Sauria: Polychridae IN COSTA RICA}

Cruz Márquez ${ }^{1}$, José Manuel Mora ${ }^{2}$, Federico Bolaños ${ }^{2}$ y Solanda Rea ${ }^{1}$,

\section{Resumen}

Se estudió Anolis aquaticus (Taylor, 1956) en la quebrada La Palma de Puriscal $\left(9^{\circ} 45^{\prime} \mathrm{N}\right.$, $84^{\circ} 27^{\prime} \mathrm{O}$ ). Métodos de muestreo sistemáticos mensuales en captura, recaptura y medidas fueron desarrollados durante el estudio. El color de ambos sexos de los $A$. $a$. es marrón con bandas verde claro verticales en el cuerpo y la cola; cuando salieron de las grietas presentaron color marrón oscuro sin bandas. El macho es de mayor tamaño que la hembra en las 13 regiones corporales medidas. Los machos mantienen en su territorio de una a tres hembras, las hembras no toleran el ingreso de otra hembra a su territorio. La proporción de sexo en la población, no varió de 1:1. Las hembras alcanzan la madurez sexual entre los 4 y 6 meses y los machos entre los 5 y 7 meses, después del nacimiento. Luego de un desove hembras menores de $64 \mathrm{~mm}$ de Longitud Hocico Ano (LHA), recuperan su peso fácilmente, mientras que hembras mayores de $64 \mathrm{~mm}$ de LHA, no lo recuperan, algunas no lo logran y mueren por inanición. Las tasas de crecimiento en LHA y peso, son aproximadamente iguales en ambos sexos adultos y difieren significativamente, de la, de los juveniles. Existe una sustancial diferencia entre las tasas de crecimiento de animales creciendo en cautiverio con los que crecen en condiciones naturales. En el porcentaje de reclutamiento, los sexos no son diferentes. Información es discutida más adelante.

Palabras Claves: Biología Poblacional, Anolis aquaticus Sauria: Polychridae.

\begin{abstract}
The lizard Anolis aquaticus (Taylor 1956) was studied at the La Palma de Puriscal Canyon, Costa Rica $\left(9^{\circ} 45^{\prime} \mathrm{N}, 84^{\circ} 27^{\prime} \mathrm{O}\right)$. A monthly sampling methodology for captures, recaptures and body measurements was developed during the study. The color of both sexes of A. aquaticus is brown, with pale green bands on the body and tail; when they emerge from the crevices they are dark brown without bands. Males are larger than females in the 13 body measurements taken. Males maintain a territory of one to three females; females do not tolerate other females within their territory. The sex ratio in the population does not vary from 1:1. Females reach sexual maturity between 4 and 6 months and males between 5 and 7 months after hatching. Following egg laying females less than $64 \mathrm{~mm}$ SVL recovered weight readily, while those of less than $64 \mathrm{~mm}$ SVL did not, some did not recover and died of starvation. Growth rates in SVL and weight are approximately equal for both sexes in adults and significantly different for the sexes in juveniles. There is a substantial difference in growth rates between captive animals and those in natural conditions. Recruitment rate was the same for both sexes. Findings are discussed in the paper.
\end{abstract}

Key words: population biology, Anolis aquaticus, Sauria: Polychridae.

\section{Introducción}

Las especies del género Anolis (Sauria: Polychridae), comúnmente conocido como anoles, se distribuyen desde Estados Unidos hasta Brasil, desde el nivel del mar hasta los 2000 msnm (Williams, 1976; Duellman, 1978; Guyer \& Savage, 1986; Frost \& Etheridge 1989; Savage \& Guyer, 1989). Anolis está entre las lagartijas más pequeñas y numerosas del infraorden Iguania, ocupan una amplia variedad de microhabitats en todo el neotrópico, desde el arbóreo al terrestre, y aún el semiacuático. Pocas especies han sido estudiadas con detalle (Campbell, 1973; Hertz, 1975; Rand \& Rand, 1976). Los anoles son de hábitos diurnos y se alimentan durante el día de invertebrados que capturan en la hojarasca y arbustos. Las presas de los adultos de $A$. limifrons (Cope, 1862), A. polylepis y $A$. garmani (Stejneger, 1899), tienen una longitud de 8-9 mm en promedio (Andrews, 1971; Sexton et al., 1972; Campbell, 1973; Andrews \& Rand, 1990). La longitud del cuerpo de los Anolis de Costa Rica, varía desde $41 \mathrm{~mm}$ (A. humilis Peters, 1863), hasta $160 \mathrm{~mm}$ (A. insignis Cope, 1871), (Savage \& Villa, 1986).

En las 27 especies dimorfas del género Anolis de Costa Rica analizadas por Taylor( 1956), Fitch (1970), y Savage \& Villa (1986), a la población de este estudio se la consideró como una subespecie de Anolis aquaticus (Taylor, 1956). Esta especie tiene subespecies en Española, Cuba y al menos en dos sitios en América Central (Savage \& Guyer, 1989; Leal et al., 2002). Por lo general, los A. aquaticus (A. 
a.), tienen extremidades largas, particularmente las traseras y colas comprimidas en sentido lateral, para facilitar su locomoción en el agua (Irschick, 1999). Las subespecies de América Central, tienen una sola forma de adaptación; son bastante similares en todas las variables morfológicas; en contraste, las dos subespecies acuáticas del Caribe, presentan varias formas de adaptación, y son sustancialmente diferentes entre ellas (Leal et al., 2002).

En la historia natural de $\operatorname{los} A$. $a$. en la isla de Barro Colorado, Panamá, en Colombia, en la mayoría de las especies de las islas del caribe (La Española, Cuba, Puerto Rico, etc.) el $75 \%$ de su dieta es de invertebrados; todas son terrestres de rivera y no se documentan especies acuáticas como pequeños camarones y peces (Leal et al., 2002). Son lagartijas que se encuentran cerca de corrientes de agua, y no se alejan más allá de $5 \mathrm{~m}$ fuera de ella. La mayoría de los A. a., usan variedad de sustrato; troncos caídos, roca y vegetación colgante permanente de rivera, donde se perchan, para cazar y huir fácilmente sumergiéndose rápidamente bajo el agua en ataques de depredadores, (Márquez, 1994; Bitt et al., 1995; Beuttell \& Losos, 1999; Leal \& Losos, 2000; Birt et al., 2001). Por lo general, $\operatorname{los} A$. a., prefieren y están restringidos a la sombra para mantener temperaturas corporales bajas entre 24.2 y $28.4^{\circ} \mathrm{C}$ (Beuttell \& Losos, 1999; Losos et al., 2002).

La evolución del dimorfismo sexual en tamaño fue uno de los primeros problemas explicados por la teoría de selección sexual (Darwin, 1871). En la mayoría de los géneros y especies de la familia Polychridae, el macho es más grande que la hembra. En general, esta diferencia se debe a selección sexual sobre los machos para ganar pleitos con otros machos. Diferencias en tamaño entre machos y hembras pueden también reducir la competencia por alimento $\mathrm{u}$ otras necesidades entre ellos (Rand, 1967). Acerca del dimorfismo sexual de $A$. $a$. en Costa Rica, no existe información detallada. En este estudio se investiga el crecimiento de las crías en cautiverio y en el campo, tasas de crecimiento en condiciones naturales, supervivencia de las crías, reclutamiento de juveniles en el campo, variación en los pesos en las hembras luego de los desoves, numero de huevos por nidos dependiendo del tamaño de la hembra, relación del abanico gular con la longitud corporal, grado de dimorfismo sexual, el tamaño corporal del animal con relación a varias regiones corporales.

\section{Materiales y Métodos \\ Área de Estudio}

Se estudiaron $\operatorname{los} A$. $a$. en la quebrada La Palma de Puriscal, Provincia de San José, Costa Rica $\left(9^{\circ} 45^{\prime} \mathrm{N}\right.$, $84^{\circ} 27^{\prime} \mathrm{O}$ ), a una altitud de $910 \mathrm{msnm}$ en una área a lo largo de la quebrada de aproximadamente $8000 \mathrm{~m}^{2}$, (Figurala-b). En la estación seca el cauce de la
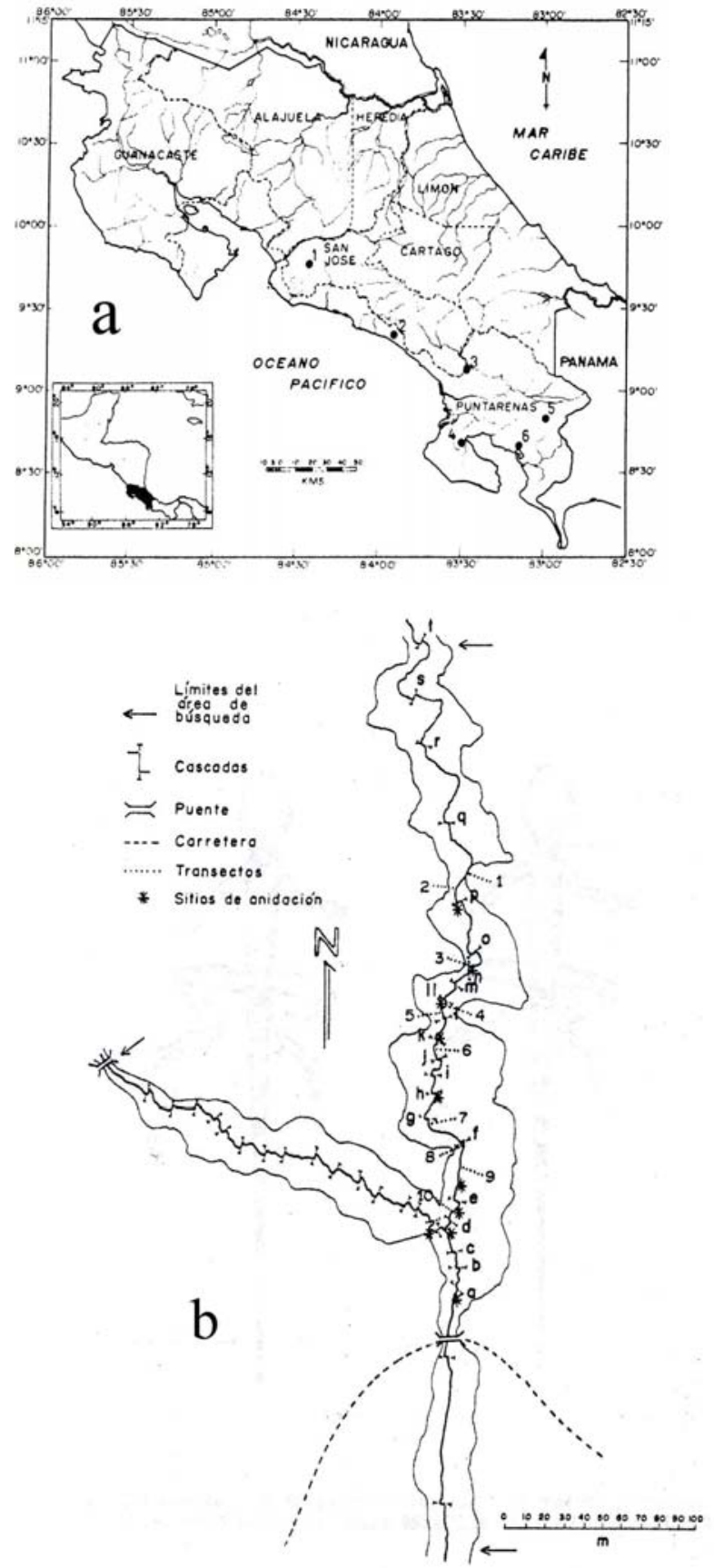

Figura 1a-b. a = Ubicación del sitio de estudio y distribución de Anolis aquaticus en Costa Rica. b = Área de estudio quebrada La Palma, de Puriscal (a-t = distribución de las cascadas).

quebrada midió $0.89 \pm 0.30 \mathrm{~m}$ en promedio (de $0.30-$ $1.44 \mathrm{n}=15$ mediciones); en la época lluviosa, su cauce mide $1.09 \pm 0.34 \mathrm{~m}$ en promedio $(0.50-1.64 \mathrm{n}=$ 15 mediciones). A lo largo de la quebrada existe un bosque ripario, arbóreo-arbustivo y herbáceo que comienza desde el borde del agua hasta 50-100m fuera de la quebrada, seguido por potreros en ambos márgenes. El sitio de estudio se encuentra localizado, 
según el sistema de zonas de vida de Holdrige, en el bosque húmedo Premontano (Valerio, 1991). Según los tipos de vegetación de Costa Rica (Gómez, 1986), se clasifica entre las formaciones estacionales con un bosque tropical húmedo de altura media. Esta es una región de clima húmedo con estación lluviosa moderada y una estación seca corta (Herrera, 1985) (Figura 1a-b).

La investigación se llevó a cabo de Marzo, 1991 a Marzo de 1993. Se trabajó con 292 individuos incluido machos, hembras y juveniles. Se diferenciaron los machos y las hembras en condiciones naturales (sin capturar) con base a las siguientes características físicas: En los machos, la región gular es de color café claro con bandas marrón y se puede percibir rasgos de su abanico gular. La región gular de la hembra es clara, sin línea longitudinal café, no se le observa rasgos de abanico gular (Figura 2a-c).
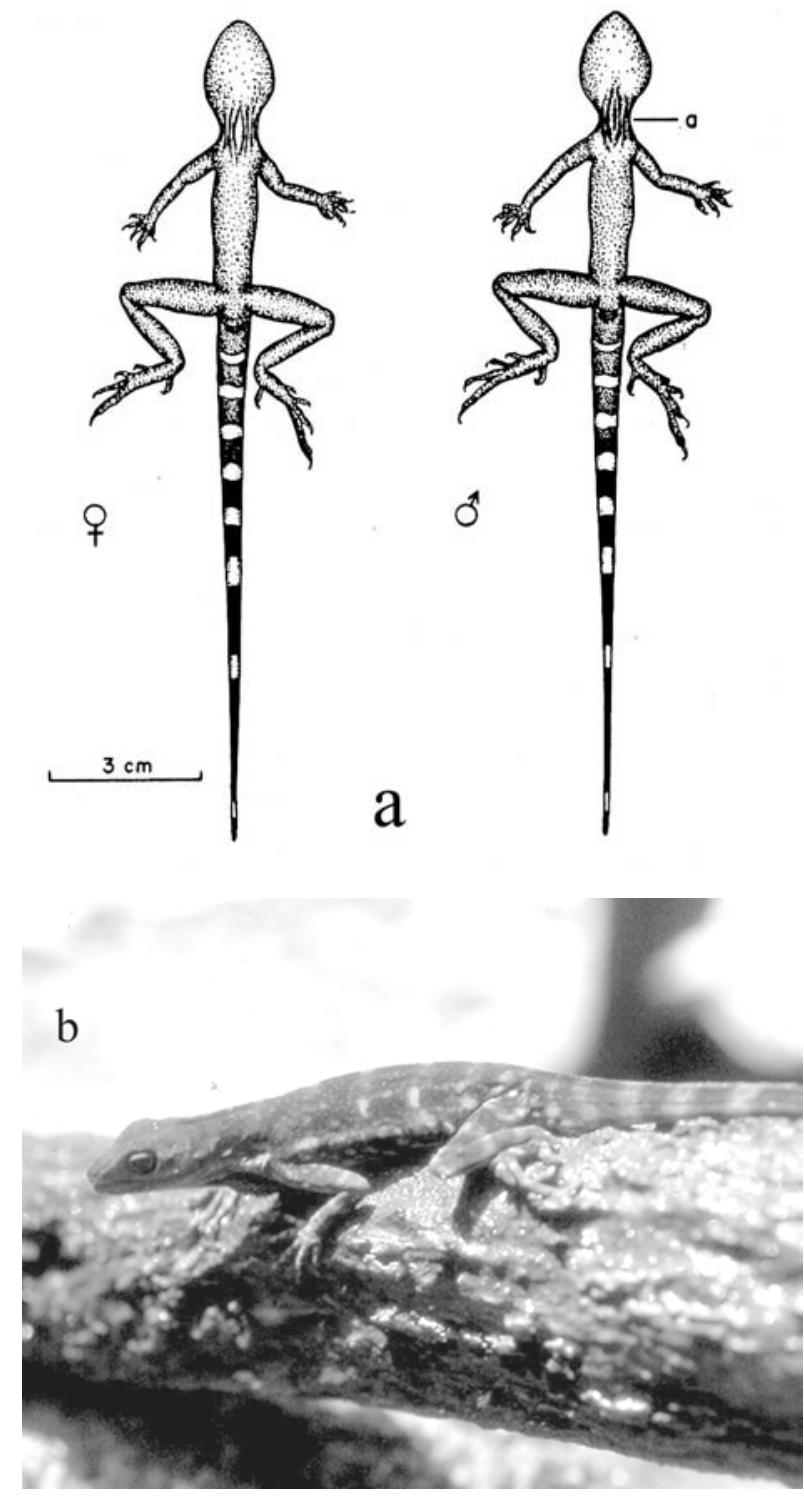

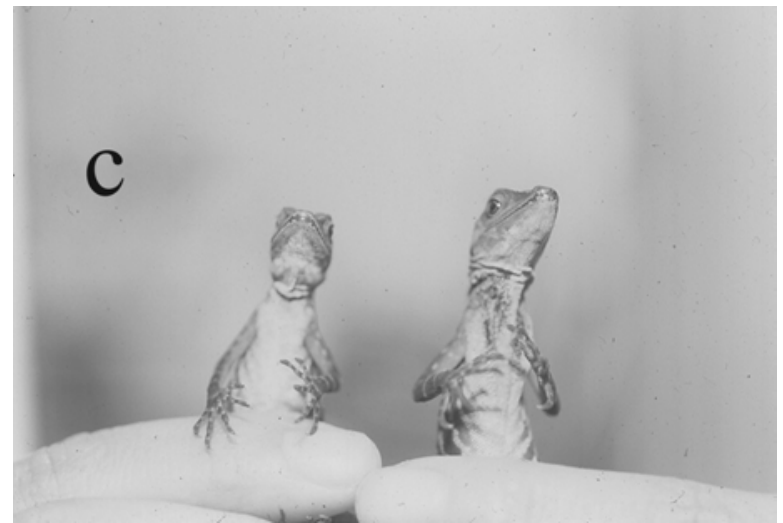

Figura 2a-c. a $=$ Diferenciación de la región ventrogular entre machos y hembras en la etapa juvenil en $A$. aquaticus, $(A$. a.); a $=$ Región ventrogular. $\mathrm{b}=$ Vista dorsal de un $A$. $a$. macho adulto, mostrando sus bandas transversales en el cuerpo y cola respectivamente. $\mathrm{c}=A$. aquaticus macho $\mathrm{y}$ hembra vista su región ventrogular. Al macho se le puede apreciar el cóndilo gular levantado y la hembra no lo muestra por no tenerlo.

Para conocer el dimorfismo sexual se utilizaron todos los parámetros corporales medidos, y el peso de los machos mayores de $55 \mathrm{~mm}$ y hembras mayores de $52 \mathrm{~mm}$ de longitud desde el hocico hasta el ano (LHA.) Para el grado de dimorfismo sexual (GDS) e índice de dimorfismo sexual (IDS), se consideró la metodología usada por Selander \& Giller (1963), en donde se usa la diferencia de los promedios dividido por la suma de los promedios en donde: $\mathrm{Xh}=$ promedio de hembras $\mathrm{Xm}=$ promedio de machos.

$$
\text { IDS =200 } \frac{\bar{X}_{h}-\bar{X}_{m}}{\bar{X}_{h+} \bar{X}_{m}}
$$

Ralls (1976) y Fitch (1981), plantean que, cuando uno de los sexos es más grande que el otro, se debe utilizar el promedio simple de tamaño de hembras dividido por el tamaño de machos y esto podría ser considerado como el grado de dimorfismo sexual (GDS):

$$
\text { GDS }=\frac{\text { Tamaño del sexo grande }}{- \text { Tamaño del sexo pequeño }^{-}}
$$

Para analizar el dimorfismo sexual de $A$. $a$. se utilizó el IDS de Selander y Giller y el GDS de Gibbons \& Lovich (1990).

Se registró la actividad diaria de los anoles, por más de 60 horas durante todo el estudio, y se registraron algunos aspectos del comportamiento en el ambiente natural, como defensa de territorio, interacciones macho entre macho, macho con 
hembras, machos con juveniles y machos con otros organismos pequeños o grandes que se acercaron a ellos.

\section{Morfometría}

Se midieron los siguientes parámetros corporales: 1) La longitud hocico ano (LHA), desde la escama mentoniana hasta el borde anterior de la cloaca; 2) El largo de la cola, desde el borde posterior de la cloaca hasta su extremo apical; 3) El diámetro dorsal de la cola a $1 \mathrm{~cm}$ posterior de la cloaca desde la región dorsal a la ventral; 4) El diámetro lateral de la cola a $1 \mathrm{~cm}$ posterior de la cloaca, desde el lado derecho al izquierdo de la cola; 5) Longitud del húmero derecho, desde la unión clavicular hasta el cóndilo humeral; 6) Longitud del cúbito-radio, desde la unión humeral hasta el cóndilo tarsal; 7) Longitud de la tibia derecha, desde la unión femoral hasta el cóndilo tarsal; 8) El largo de la cabeza, desde la escama rostral hasta el occipital; 9) El ancho de la cabeza, desde el borde supraocular derecho al izquierdo; 10) Largo del 2do y 5to dedo de la pata posterior izquierda, y el 3er dedo de la pata anterior derecha, desde la base de la uña hasta la membrana que une los dedos; 11) El peso de cada individuo, se obtuvo al colocarlo en una bolsa plástica de peso conocido y suspenderlo con una pesola de 10 y 50 g. Se midió también el diámetro del abanico gular (papada) extendido, los testículos de los machos y los oviductos de las hembras.

Se disectaron 11 hembras y 12 machos que medían entre 37.45-77.0 $\mathrm{mm}$ de LHA respectivamente, para determinar la madurez sexual de machos y hembras. Las gónadas fueron observadas y medidas en un estereoscopio Reichert Zoom.

Para estimar la tasa de crecimiento se dividió el incremento de crecimiento en milímetros por el tiempo en días desde la primera hasta la última captura. El reclutamiento fue cuantificado mediante las capturas y recapturas de los individuos juveniles.

El análisis estadístico se llevó a cabo por medio del paquete estadístico, SPSS; con Ji-cuadrado, se comparó la proporción sexual de los Anolis, El dimorfismo sexual por Análisis de Varianza y Kruskal Wallis, involucrando todos los parámetros medidos. Se utilizó un análisis de correlación y regresión lineal para la relación del tamaño del testículo y la longitud del cuerpo y la relación tamaño del cuerpo asociado con el diámetro del abanico gular (papada) y algunas regiones corporales medidas (Zar, 1999).

\section{Resultados}

\section{Di-cromatismo Sexual}

El color de ambos sexos de $\operatorname{los} A$. $a$. fue marrón con bandas verde claro en el cuerpo y la cola. Los machos presentaron en el cuerpo 7-8 bandas verde claro, y 10-12 bandas del mismo color en la cola $(\mathrm{n}=$ 21). Las hembras mostraron en el cuerpo el mismo color y número de bandas que los machos, pero 9-11 bandas en la cola $(n=23)$. Sin embargo, el color podía cambiar. Cuando se capturó un Anolis en las grietas o fisuras, el color del cuerpo era marrón sin bandas, pero luego de 30-50 seg. de estar afuera las bandas de color verde claro volvieron visibles. El abanico gular del macho, es oscura su región ventrogular; la región ventrogular de la hembra es clara, y sin abanico gular. Los machos fueron más grandes en el tamaño corporal, cola y peso que las hembras (Figura 2a-c).

Grado (GDS) e Índice (IDS) de Dimorfismo Sexual

El grado de dimorfismo sexual (GDS) de $A$. $a$. machos y hembras en LHA y peso fue de 0.88 y 0.76 , respectivamente, y el índice de dimorfismo sexual fue $-12.96 \%$ en LHA y $-27.50 \%$ en peso. Así las hembras fueron más pequeñas que los machos.

En más de 60 horas de observación, se vio que un macho mantuvo en su territorio de 1 a 3 hembras, distantes $(2.0$ a $2.5 \mathrm{~m})$ una de otra. Ningún macho adulto o subadulto pudo acercarse a menos de $2 \mathrm{~m}$ de distancia al territorio de otro macho. Un macho adulto territorial, si permitió el acercamiento de juveniles a su territorio. Siempre que se acerco una hembra, otro macho, un juvenil o una pequeña ave "reinita guarda rivera" (Manacus candei) al territorio de un macho; el macho siempre realizó movimientos de flexiones de pecho. Las hembras también mostraron territorialidad, ninguna hembra tolero el acercamiento de otra a menos de 2.0 de distancia.

La comparación morfométrica de las distintas regiones corporales de $A$. $a$., en machos mayores de 55 mm en LHA y hembras mayores de $52 \mathrm{~mm}$ de LHA, mostraron que los machos y las hembras difieren en todas las regiones corporales medidas (Tabla 1). Se correlacionó la LHA con 4 parámetros corporales, e indicó que los machos difieren significativamente de las hembras; se exceptuó la longitud del húmero, las pendientes no fueron diferentes (Figura 3a-d).

Tabla 1. Análisis de varianza de 13 parámetros corporales comparando machos y hembras.

\begin{tabular}{llll} 
Variables & $\begin{array}{l}\text { Razón } \\
\text { de sexo }\end{array}$ & g. 1. & Probabilidad \\
\hline Longitud cuerpo & 0.07 & 167 & 0.001 \\
Longitud cola & 0.11 & 167 & 0.008 \\
Ancho cabeza & 0.07 & 139 & 0.004 \\
Longitud húmero & 0.82 & 136 & 0.002 \\
Longitud dedo largo R. Interna & 0.78 & 130 & 0.005 \\
Longitud dedo largo R. Externa & 0.66 & 135 & 0.003 \\
Peso (g) & 0.95 & 167 & 0.007 \\
Tibia derecha & 0.75 & $30 *$ & 0.001 \\
Dedo Central & 0.58 & $27 *$ & 0.002 \\
Radio derecho & 0.72 & $27 *$ & 0.001 \\
Dedo posterior derecho & 0.73 & $30 *$ & 0.001 \\
Cola lateral & 0.22 & $26 *$ & 0.001 \\
Cola dorsal & 0.97 & $26 *$ & 0.001 \\
\hline
\end{tabular}

* = Análisis con una prueba de Kruskal-Wallis, por ser muestras pequeñas, $\mathrm{R}=$ Región 

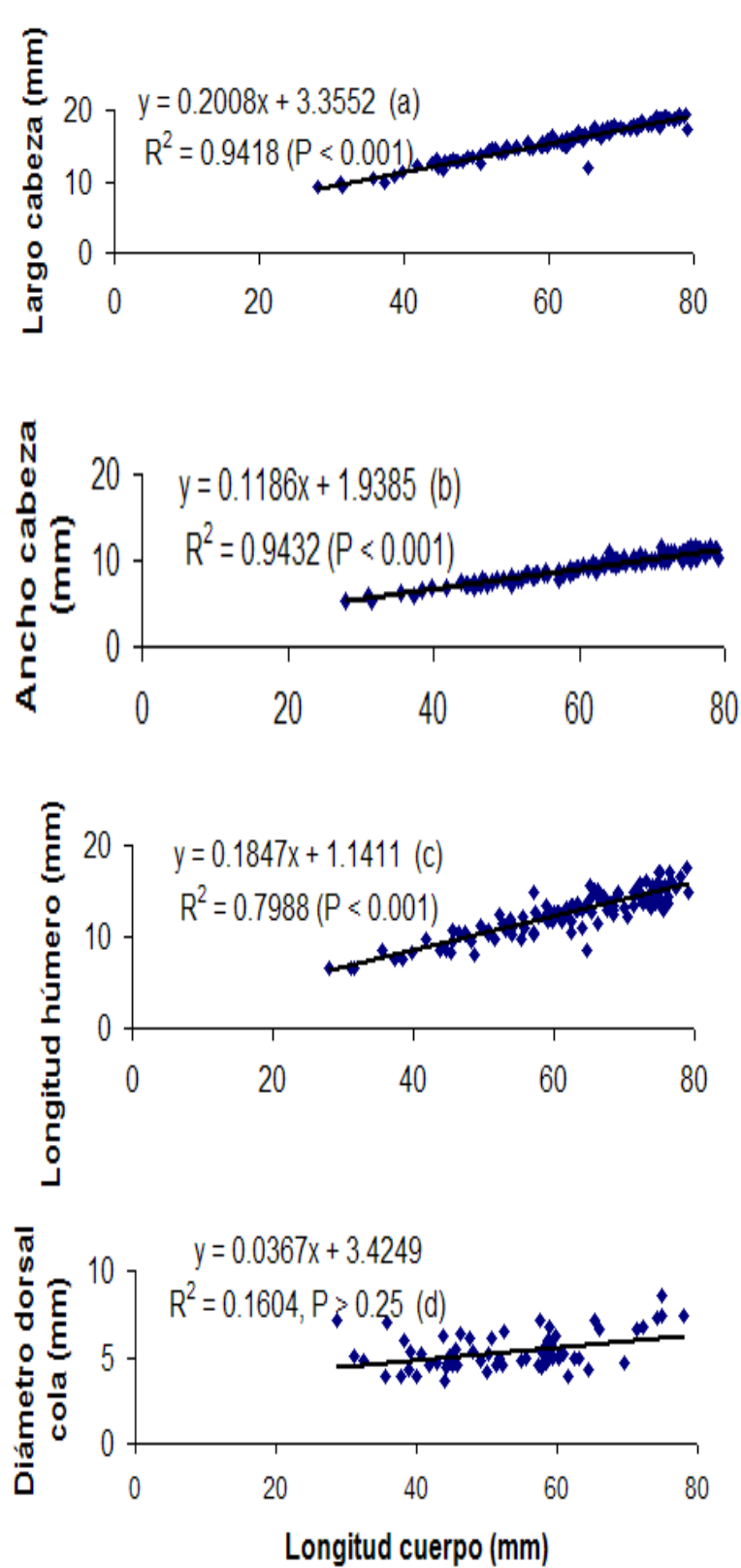

Figura 3a-d. Relación de la longitud hocico ano con otros parámetros corporales medidos 29 machos y 34 hembras de $A$. aquaticus de la quebrada La Palma de Puriscal $=$ Largo de la cabeza. $\mathrm{b}=$ Ancho de la cabeza. $\mathrm{c}=$ Longitud húmero. $\mathrm{d}=$ diámetro dorsal de la cola.

Las proporciones y razón de sexo en los 167 individuos adultos observados, no variaron de 1:1 (83 machos, 84 hembras). No hubo diferencia en las proporciones de sexo entre meses y estaciones del año $\left(\mathrm{X}^{2}=4.48\right.$, g. $1 .=6, \mathrm{P}>0.75$. En cuanto a los porcentajes de recapturas, los machos fueron mayormente recapturados y diferentes de hembras y juveniles $\left(X^{2}=54.94\right.$, g. $\left.1 .=32, P<0.01\right)$. Se exceptúan los meses de Julio de 1991, febrero de 1992, Septiembre a Noviembre de 1992 y Febrero de
1993, que no fueron diferentes $\left(X^{2}=13.45\right.$, g. $1 .=10$, $\mathrm{P}>0.25)$; en Mayo y Junio, no se recapturaron juveniles (Figura 4).

\section{Madurez Sexual de Machos y Hembras:}

\section{Los Machos}

Se disectaron 12 machos de $38.2-77.2 \mathrm{~mm}$ en LHA. En cinco machos menores de $50.02 \mathrm{~mm}$ de LHA, los testículos midieron de 1.5 - 2.5 X $1.4-1.9$ $\mathrm{mm}$ y sus tubos seminales solo presentaron una línea de color café ubicada sobre el riñón, la cual midió 55.9 X 0.05-0.10 mm. No se observó hemipenes (Figura 5a-b).

Los testículos de un macho de $56.10 \mathrm{~mm}$ de LHA, midieron $4.8 \times 3.4 \mathrm{~mm}$, sus tubos seminales tuvieron una longitud de $7.2 \times 0.4 \mathrm{~mm}$; y presentaron forma serpentinada de color café claro y punteado, en el extremo apical de los tubos seminales, se encuentran presentes los hemipenes (Figura 5a-b). A este animal y otros machos mayores de $56 \mathrm{~mm}$ de LHA se les extrajo por los hemipenes líquido seminal de color blanquecino, el cual fue examinado al microscopio. Se encontró testículos presentes en la revisión de las gónadas de los machos mayores de $38 \mathrm{~mm}$ en LHA. Existe una relación directa proporcional significativa entre la longitud corporal y el tamaño de los testículos de los Anolis $\left(\mathrm{r}^{2}=0.98, \mathrm{P}<0.001\right)$. Se observó que el tamaño de los testículos corresponde al 6.9 - 8.8\% de la longitud corporal del animal (Figura 6).

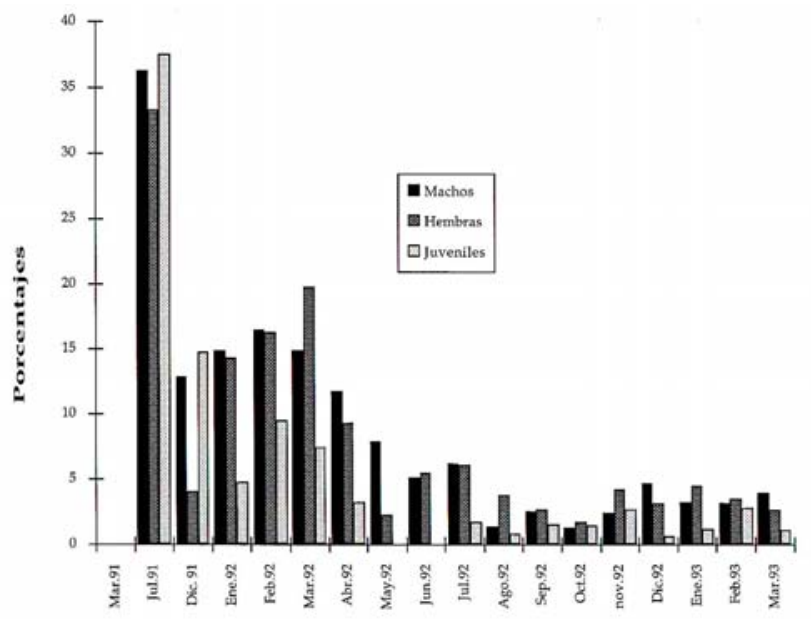

Figura 4. Porcentaje de A. aquaticus machos, hembras y juveniles recapturados según mes en la quebrada La Palma de Puriscal.

En el conjunto de medidas diámetro del abanico gular (papada) de los machos, se observó que el tamaño del mismo corresponde al $35.4 \%$ en promedio $(8.47-42.1 \%)$, con relación a la longitud corporal del animal. Existe una relación directamente proporcional significativa entre la longitud hocico ano (LHA) y el tamaño del abanico gular $\left(\mathrm{r}^{2}=0.91, \mathrm{P}<0.001\right.$, Figura $7 a-b)$. 


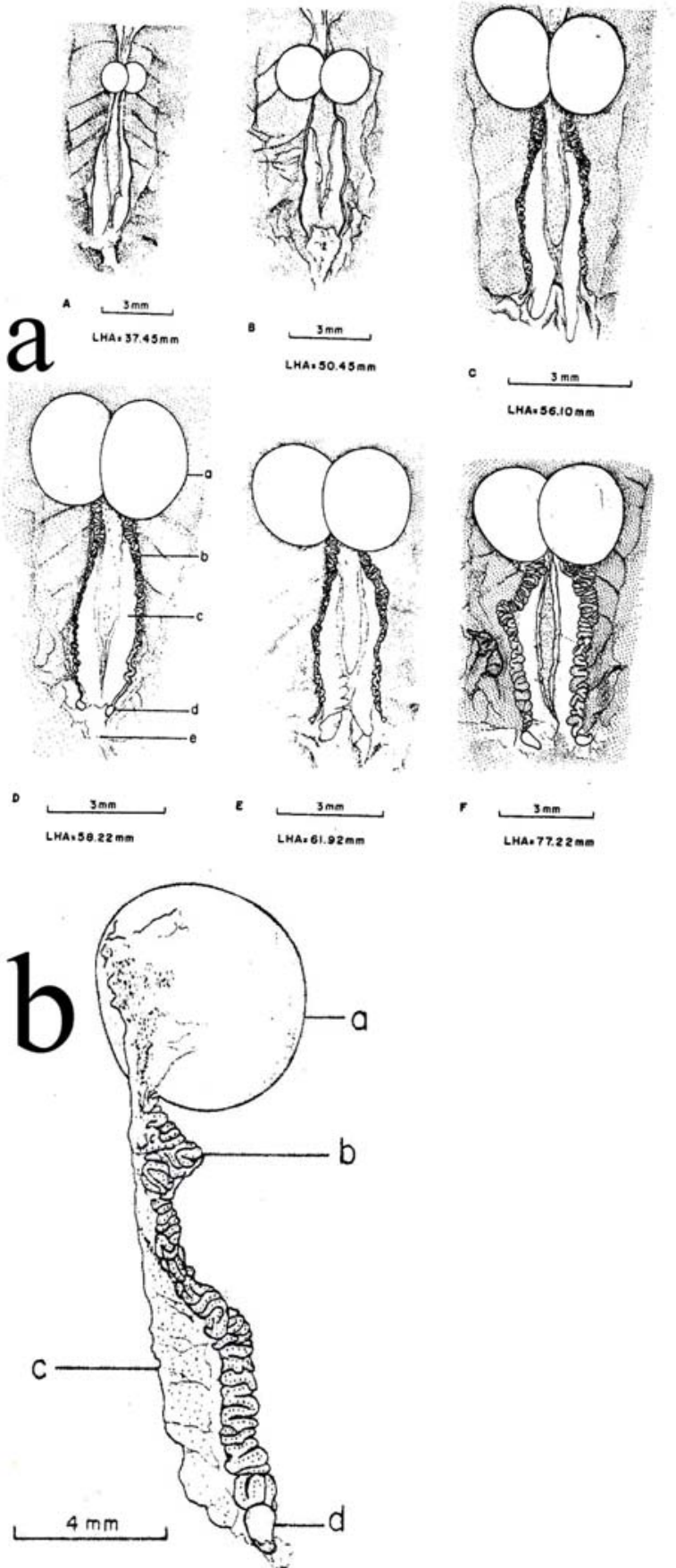

Figura 5a-b. a = Madurez sexual de gónadas de $A$. aquaticus machos (a) Testículos, (b) Tubos seminíferos, (c) Riñón, (d) Hemipenes, (e) Cloaca. b = Gónada de $A$. aquaticus macho, vista ventral.

\section{Las Hembras}

Se pesaron las hembras capturadas en condiciones naturales, antes y después de la disección. Al retirarles un huevo del oviducto, la hembra perdió un $13.7 \%$ del peso en promedio $(\mathrm{N}=8)$, con rangos desde 11.5 - 16.7\%; y al sacarle dos huevos de los oviductos, disminuyeron un $21.5 \%$ del peso en promedio $(\mathrm{N}=3)$. Al pesar dos hembras cautivas antes y después del desove perdieron un $13,8 \%$ del peso en promedio; y cuatro hembras al desovar dos huevos disminuyeron un $21.7 \%$ del peso en promedio, con un rango entre (17.6-24.0\%). En condiciones naturales se encontraron algunas hembras que habían disminuido su peso de un mes a otro o de una captura a otra, cuyo porcentaje fue próximo al anterior indicado. En la palpación de los huevos en el vientre de las hembras, se observo también que hembras grandes tenían de 2 a 3 huevos y las pequeñas, de 1-2 en las bolsas oviductales.

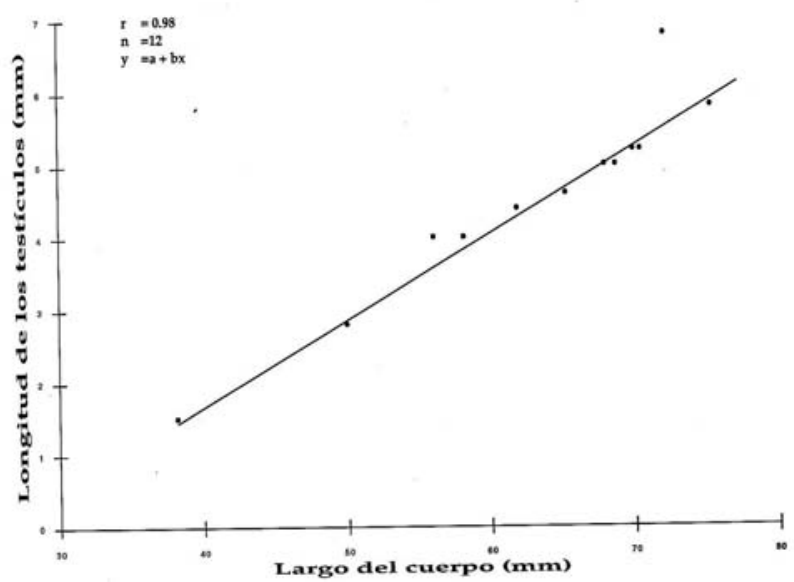

Figura 6. Longitud de los testículos con relación al largo del cuerpo de A. aquaticus Macho.

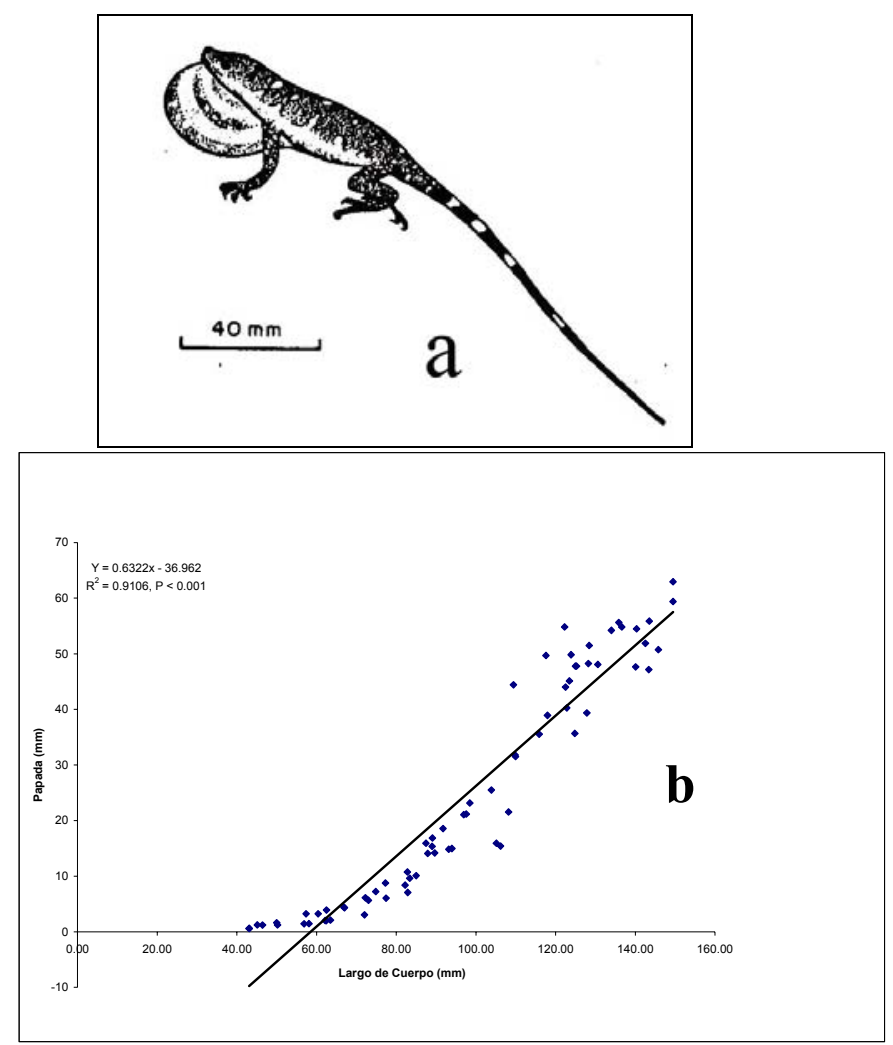

Figura 7a-b. $\mathbf{a}=$ A. aquaticus macho en despliegue de abanico gular. $b=$ Relación entre la Longitud del cuerpo y el diámetro del abanico gular (papada). 
Las 11.hembras disectadas fluctuaron entre $36.7 \mathrm{y}$ $65.8 \mathrm{~mm}$ en LHA. En las hembras menores de 48.02 mm de LHA, los oviductos aún no estaban definidos. Solamente se observó una línea blanca transparente extendida a lo largo y sobre el riñón. Los tamaños de los oviductos fueron de $5.8-6.2 \times 0.6-1.1 \mathrm{~mm}$. El tamaño de los ovarios fue de $1.2-1.8 \times 0.6-0.9 \mathrm{~mm}$ compuesto por 3 - 4 lóbulos (Figura 8a-c).

Una hembra de $52.32 \mathrm{~mm}$ de LHA, presentó un huevo en desarrollo en su oviducto derecho, el cual midió 10.5 x $1.8 \mathrm{~mm}$, y sus ovarios $1.5 \times 1.20 \mathrm{~mm}$, con 3 - 4 lóbulos. Las gónadas de las hembras con tallas de 52.38 - $65.82 \mathrm{~mm}$ de LHA, en general, estaban bien desarrolladas. Sus ovarios estaban formados por 3 - 4 lóbulos y siempre tuvieron 1 ó 2 huevos en proceso de formación. Los oviductos de dos hembras de 51.3 - $51.4 \mathrm{~mm}$ en LHA, midieron 7.0 $7.20 \times 1.0-1.1 \mathrm{~mm}$, sus ovarios de $2.20-2.30 \times 1.0-$ $1.1 \mathrm{~mm}$ con 3 - 4 lóbulos en etapa de premadurez, ya que no estaban bien definidas. No se disectaron hembras de los tamaños 48.03 - $51.2 \mathrm{~mm}$ de LHA (Figura 8a-c).

En el conjunto de medidas de los oviductos de las hembras disectadas, se observó que el tamaño de ellos, corresponde al $12.2 \%$ en promedio $(11.0-15.1 \%)$, de la longitud corporal del animal. Se encontró que existe una relación proporcional significativa entre la longitud hocico ano (LHA) y el largo de los oviductos $(\mathrm{r}=0.389, \mathrm{P}<0.05)$.

\section{Nacimiento y tamaño de las crías}

Dos neonatos (un macho y una hembra), nacieron en cautiverio, con un LHA de 25.3 y $25.3 \mathrm{~mm}$ y $0.7 \mathrm{~g}$. de peso. La cola de la hembra fue de $38.32 \mathrm{~mm}$ de largo y la del macho $37.24 \mathrm{~mm}$. En condiciones naturales se capturaron y midieron solo dos individuos de ese tamaño (ambos $26 \mathrm{~mm}$ de LHA y $0.6 \mathrm{~g}$ de peso). De acuerdo al peso que perdieron y la talla que ganaron los 2 neonatos en 9 días en cautiverio, se estima que las crías capturadas en el campo tenían aproximadamente entre 10 a 15 días de eclosionados.

\section{Tasas de Crecimiento de las crías}

Después de eclosionar, se mantuvieron ambas crías encerradas en la misma incubadora por 9 días y se les ofreció pequeñas mariposas y moscas para su alimentación; sin embargo, ninguno de los dos neonatos comió. La hembra en 9 días incrementó $2.5 \% \mathrm{~mm}$ en LHA y el macho $1.5 \% \mathrm{~mm}$ con relación al LHA inicial. La hembra tuvo una tasa de crecimiento de $0.07 \mathrm{~mm} /$ día y el macho $0.04 \mathrm{~mm} /$ día. Ambos animales perdieron $14.29 \%$ de su peso inicial en los 9 días de observación.

De los 76 animales, 22 (12 machos y 10 hembras) midieron menos de $32 \mathrm{~mm}$ de LHA, cuando se los capturó por primera vez. Al revisar las gónadas, de una muestra de 23 individuos, se encontró que las hembras cuando han logrado una talla mayor a los 52 $\mathrm{mm}$ en LHA, a una edad de 4 - 6 meses, son sexualmente maduras. Mientras que los machos son maduros sexualmente, cuando han ganado un tamaño mayor a $55 \mathrm{~mm}$ en LHA, a una edad de 5-7 meses.

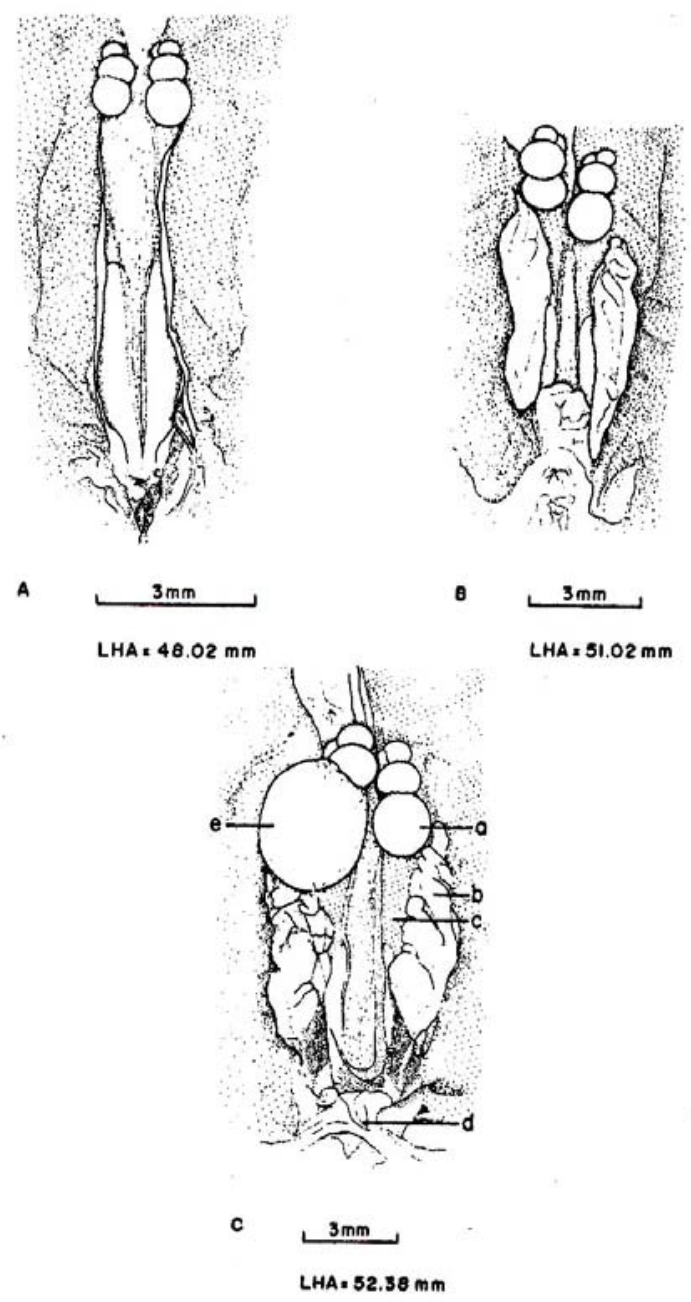

Figura 8 a-c. Madurez sexual de gónadas de $A$. aquaticus hembras (a) ovarios, (b) oviductos, (c) riñón, (d) cloaca, (e) huevo en desarrollo.

En condiciones naturales, 34 machos de $A$. $a$. fueron recapturados de 3 a 8 veces, y 28 hembras de 3 a 7 veces $\left(23\right.$ y $\left.35{ }^{\Uparrow}\right)$ y 14 juveniles de 3 a 6 veces. Los machos presentaron tasas de crecimiento $\bar{X}=$ $0.05 \mathrm{~mm} /$ día y $0.01 \mathrm{~g} /$ día. Las hembras mostraron tasas de crecimiento $\bar{X}=0.04 \mathrm{~mm} /$ día y $0.01 \mathrm{~g} /$ día. Las hembras juveniles, menores de $52 \mathrm{~mm}$ en LHA presentaron tasas de crecimiento de $\bar{X}=0.11 \mathrm{~mm} /$ día y $0.02 \mathrm{~g} /$ día. Mientras que los machos juveniles menores de $54 \mathrm{~mm}$ en LHA mostraron tasas de crecimiento de $0.23 \mathrm{~mm} /$ día y $0.02 \mathrm{~g} /$ día. Estas tasas, fueron mayores que la que presentaron los 2 neonatos en cautiverio y las de los adultos de ambos sexos mencionados anteriormente (Tabla 2). No hubo diferencia en las tasas de crecimiento entre las hembras y los machos adultos $(\mathrm{t}=1.39$, g. $1 .=118, \mathrm{P}$ 
$>0.10$ ); pero las tasas de crecimiento de los machos y hembras juveniles, fueron mayores y diferentes que las de las hembras y machos adultos (Tukey $=\mathrm{P}<$ $0.05)$.

Tabla 2. Tasas de Crecimiento (TC) promedio de longitud corporal y peso por día, de Anolis aquaticus machos mayores de 54 , hembras mayores de 52 y hembras juveniles menores de 52 y machos juveniles menores de $54 \mathrm{~mm}$ en LHA recapturados durante 17 meses (1991-1993), en la quebrada La Palma de Puriscal.

\begin{tabular}{|c|c|c|c|c|c|}
\hline $\mathrm{N}$ & Sexo & $\begin{array}{c}\bar{X}_{\mathrm{TC} / \mathrm{día}} \\
(\mathrm{mm})\end{array}$ & Rango & $\begin{array}{c}\bar{X}_{\text {TC/día }} \\
(\mathrm{g})\end{array}$ & Rango \\
\hline
\end{tabular}

\begin{tabular}{|c|c|c|c|c|c|}
\hline 34 & गे $>54 \mathrm{~mm}$ & $0.05 \pm 0.04$ & $\begin{array}{l}0.02- \\
0.16\end{array}$ & $0.01 \pm 0.01$ & $0.01-0.03$ \\
\hline 28 & $q>52 \mathrm{~mm}$ & $0.04 \pm 0.03$ & $\begin{array}{l}0.01- \\
0.11\end{array}$ & $0.01 \pm 0.01$ & $0.01-0.03$ \\
\hline 23 & $\mathrm{~J} q<52 \mathrm{~mm}$ & $0.11 \pm 0.04$ & $\begin{array}{l}0.01- \\
0.21\end{array}$ & $0.02 \pm 0.01$ & $0.01-0.04$ \\
\hline 35 & $\mathrm{~J}^{\Uparrow}{ }^{\lambda}<54 \mathrm{~mm}$ & $0.23 \pm 0.14$ & $\begin{array}{l}0.04- \\
0.28\end{array}$ & $0.02 \pm 0.01$ & $0.03-0.04$ \\
\hline
\end{tabular}

Las curvas de crecimiento mostraron diferencias de forma y tamaño entre los sexos (Figura 9a-b). Al correlacionar cada valor de LHA de 10 hembras y 10 machos con el peso, se obtuvieron curvas de crecimiento, mostrando que machos con tamaños mayores a $69 \mathrm{~mm}$, ganan longitud pero pierden del 5 al $10 \%$ de su peso $(\mathrm{r}=0.98, \mathrm{P}<0.001)$. Un comportamiento similar se observó en las hembras, las cuales al llegar a una talla mayor de $59 \mathrm{~mm}$ de LHA, perdieron del 13.7 a $21.7 \%$ de su peso $(\mathrm{r}=0.92, \mathrm{P}<$ 0.001 ), el cual fue recuperado luego de algunos días y meses. Pero cuando los machos han sobrepasado los $70 \mathrm{~mm}$, el peso es muy variable; es decir, disminuyen y nivelan el peso entre un mes a otro. Condición similar ocurrió con las hembras, cuando sobrepasaron los 60mm en LHA (Figura 9a-b y 10a-j).

Reclutamiento y permanencia de juveniles, machos y hembras en el sitio de estudio

El reclutamiento de machos jóvenes fue $37 \%$ y el de las hembras $25.4 \%$, durante los 18 meses de muestreo. No hubo una diferencia significativa entre machos y hembras en el porcentaje de reclutamiento $\left(\mathrm{X}^{2}=3.48\right.$, g. $\left.1 .=1, \mathrm{P}>0.05\right)$. La probabilidad de volver a ser capturado un individuo en el área de estudio fue, para juveniles y machos adultos de $51.6 \%$ y de hembras jóvenes y adultas fue de $40.1 \%$. La permanencia mínima para machos y hembras fue de un mes (2 recapturas). El número máximo de recapturas fue de 8 veces en 17 meses, para los machos y de 7 veces para las hembras.

\section{Discusión \\ Di-cromatismo Sexual}

Cuando los $A$. aquaticus machos y hembras son sacados de los refugios, luego de 30-50 seg. de estar afuera aparecen bandas de color verde claro en el cuerpo y cola. Las hembras de 9-11 en la cola, el cuerpo presenta el mismo patrón de color de los machos. Según Young (1977), el color de los anoles, puede cambiar de acuerdo con el ambiente, en respuesta a la temperatura y otras variaciones ambientales. Este mismo autor indica, que probablemente en estas lagartijas, no existen nervios que vayan a los melanóforos, los cuales son controlados mediante hormonas producidas por el lóbulo posterior de la hipófisis y otras glándulas; como ocurre en los camaleones. No es claro si un cambio tan rápido como el de los $A$. $a$. puede deberse a cambios hormonales.

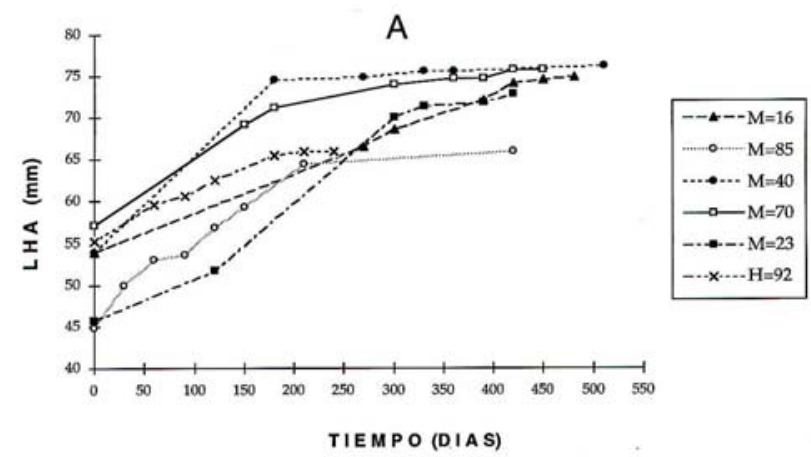

B

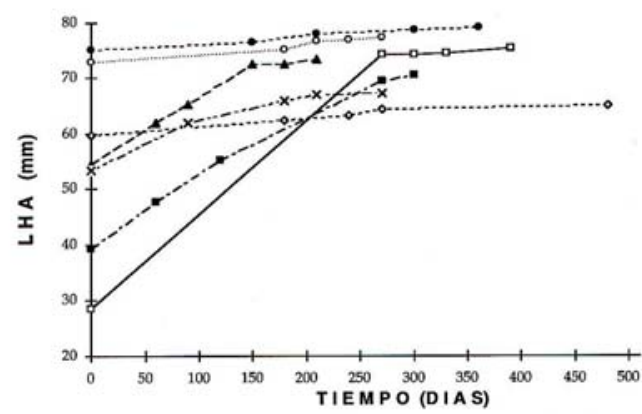

Figura 9a-b. Curvas de crecimiento en LHA de diez machos y tres hembras, de acuerdo al número de días, después de la primera captura de $\operatorname{los} A$. a. de la quebrada La Palma de Puriscal. $(\mathrm{M}=$ machos, $\mathrm{H}=$ hembras, LHA = longitud hocico ano).

\section{Grado e Índice de Dimorfismo Sexual}

Los valores del análisis del grado de dimorfismo sexual de $A$. a., es $0.88 \mathrm{~mm}$ en LHA y $0.76 \mathrm{~mm}$ en peso. Las 13 regiones corporales medidas mostraron que los machos son más grandes que las hembras; el índice de dimorfismo sexual, también sugirió que los machos son más grandes que las hembras. En las 27 especies de anole de Costa Rica, y en la mayoría de las especies de la familia Polychridae, el macho es más grande que la hembra (Savage \& Villa, 1986; Leal et al., 2002). Lo antes dicho contrasta con lo afirmado por Price (1984) y Carothers (1984), quienes indican que en algunos reptiles, las hembras son más grandes que los machos por el requerimiento de llevar los huevos y tener mejor éxito reproductivo. Gibbon 
\& Lovich (1990), afirman que en los anoles, los machos son más grandes que las hembras, por ventajas competitivas en los encuentros machomacho en presencia de una hembra. Las diferencias en tamaños, entre machos y hembras, reduce la competencia entre los sexos, por comida y otras necesidades (Price, 1984; Carothers, 1984; Selander, 1972).

En los $A$. $a$. machos, el tamaño del abanico gular, es proporcional a la longitud corporal, y es más que el $35 \%$ con relación al tamaño del cuerpo. Los machos mediante despliegues de el abanico gular, anuncian su presencia ante otros machos, ante otros animales pequeños o grandes que se acerquen a él, ante las hembras para atraerlas e incitarlas a copular. Crews (1973), observó que al cortar el cartílago hioideo a machos cautivos de A. carolinensis, éstos no levantaron su abanico gular al cortejar a una hembra, y que éstas no respondieron sexualmente a los despliegues de cortejo de los machos. Andrews (1971), indica que las manifestaciones de despliegue de abanico gular, los machos lo usan, para anunciar su presencia ante hembras y otros machos y para cortejar a las hembras.

Los machos maduros de $A$. $a$. presentan testículos esféricos grandes del $8.6 \%$ con relación al tamaño corporal, y un tubo seminal serpentinado, sin estirar es del $12.9 \%$ y estirado es próximo a la longitud corporal del mismo. Rueda (1989) encontró que los machos de A. megalopithecus presentaron testículos esféricos y bien desarrollados. En las hembras, la longitud de los oviductos es el $12 \%$ con relación a la longitud corporal del animal, existe una relación proporcional entre la longitud corporal, el tamaño de los oviductos y la cantidad de huevos que una hembra puede desovar.

Las hembras de $A$. $a$. después de haber eclosionado, alcanzan la madurez sexual entre los 4-6 meses; cuando han alcanzado una talla $>52 \mathrm{~mm}$ en LHA. Los machos después de haber eclosionado, logran la madurez sexual entre los 5-7 meses; cuando han logrado una talla $>55 \mathrm{~mm}$ en LHA. Otras especies como las lagartijas semiacuáticas $A$. lionotus, o Norops oxylophus (Cope, 1861, 1875) y A. poecilopus (Cope, 1862), alcanzan la madurez sexual entre los 2-3 meses después de eclosionados (Campbell, 1973).

La razón de sexos en esta población de lagartija durante los meses del año no es variable y siempre se mantiene cerca al 1:1. Esto sugiere que no existe un fuerte limitante como efecto negativo de depredación en los tres estratos de la población de esta lagartija, en ambas estaciones del año, que permitan disminuirlos y desbalancear la abundancia de individuos en la población. Las proporciones de sexo de las capturas y recapturas no son diferentes entre los sexos, corroboran indicando que tanto machos como hembras se exponen al ambiente en igual número.
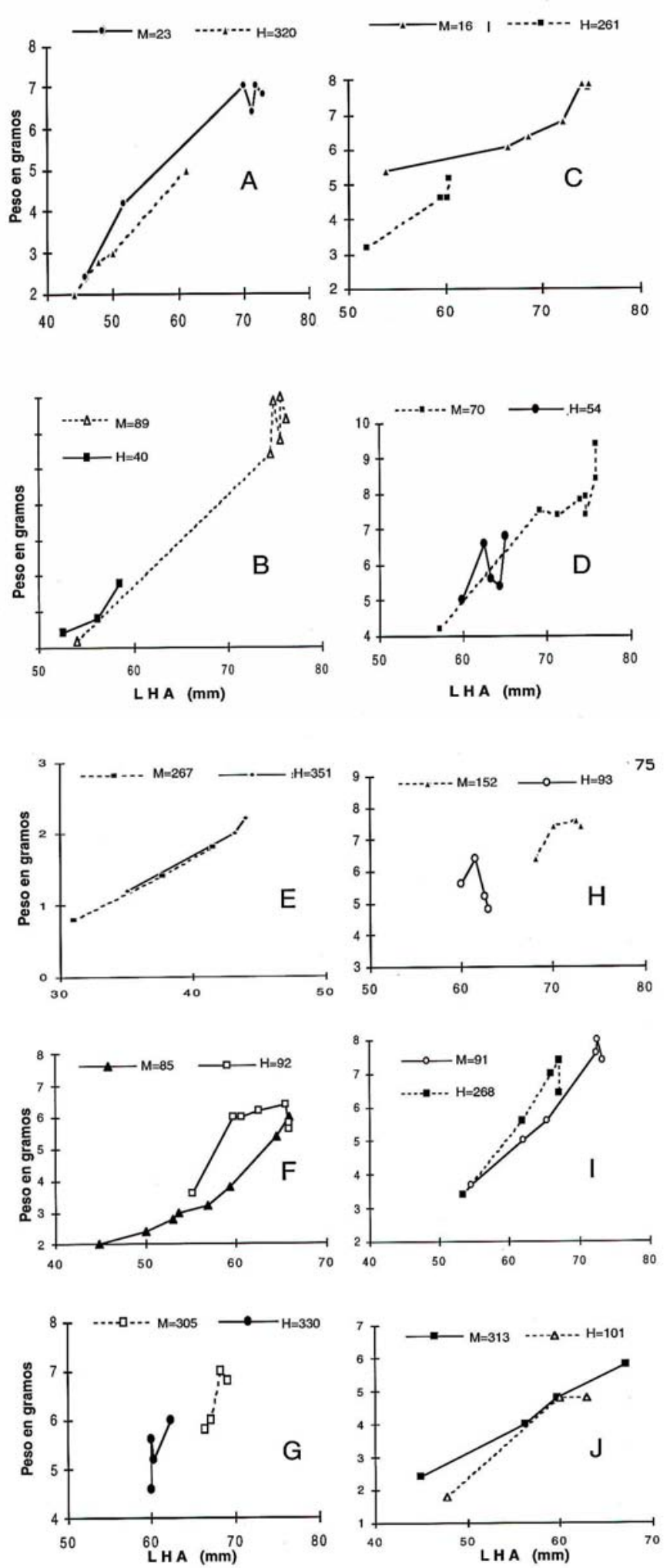

Figura 10a-j. Relación de la longitud hocico ano con el peso de diez machos y diez hembras de $A$. aquaticus, más frecuente recapturados en la quebrada La Palma de Puriscal. Cada gráfico corresponde a un macho y una hembra ( $\mathrm{M}=$ machos, $\mathrm{H}=$ hembra $)$. 


\section{Tasas de Crecimiento}

Los A. a., incluido los tres estratos de la población, muestran tasas de crecimiento promedio de 0.04 a $0.23 \mathrm{~mm} /$ día (con ámbitos de 0.02 a $0.28 \mathrm{~mm} /$ día) y peso promedio de 0.02 a $0.04 \mathrm{~g} /$ día. Los valores encontrados en $A$. poecilopus (Cope, 1862; 0.30$0.48 \mathrm{~mm} / \mathrm{mes}$ ) por Campbell (1973), caen por debajo de los ámbitos de este estudio. Sin embargo, en los machos y las hembras adultas mayores de 74 y $64 \mathrm{~mm}$ en LHA respectivamente, el crecimiento es lento y tiende a cero. En la iguana verde, la tasa de crecimiento en LHA es $0.23 \mathrm{~mm} /$ día y disminuye por el alto nivel de actividad territorial en los machos, y por el desove en las hembras (Werner \& Rey, 1994). Las tasas de crecimiento diarias en longitud de cuerpo de la iguana verde, es superior a las obtenidas en los anoles de este estudio en la misma dimensión corporal.

Las tasas promedio de crecimiento entre ellos, no son diferentes, excepto la de los juveniles, que son diferentes de la de los machos y hembras adultos. Los anoles en condiciones naturales, presentan tasas de crecimiento mayores, pero no diferente a los que se desarrollan en cautiverio. La relativa diferencia en las tasas de crecimiento entre los animales de cautiverio y los de condiciones naturales, puede tener relación con presencia de estrés, por la reducción de espacio ambiental, que no le permite libertad para buscar y elegir perchas estratégicas para capturar libremente sus presas preferidas, y por la no disponibilidad de corrientes de agua, que le facilite la huida del depredador. Los niveles de corticosterona en el plasma de los reptiles, es usado a menudo como indicador de estrés fisiológico en poblaciones que viven en estado salvaje. Es posible que la captura, manipulación y encierro son estresantes intensos para estos animales (Romero \& Wikelski, 2001).

Los machos mayores de $69 \mathrm{~mm}$ en LHA, de un mes a otro ganan longitud de cuerpo, pero pierden entre el 5 y $10 \%$ de su peso. Las hembras mayores de $59 \mathrm{~mm}$ de LHA, de un mes a otro ganan longitud de cuerpo, pero pierden entre el 13.7 al $21.8 \%$ de su peso; la biomasa se recupera luego de algunos días o meses posteriores al desove siempre y cuando las hembras sean menores a los $63 \mathrm{~mm}$ de LHA. Las hembras mayores de $63 \mathrm{~mm}$ de LHA, no recuperan el peso luego del desove y siguen perdiéndolo hasta llegar a ser esqueléticas; mueren por inanición probablemente por ser muy viejas. Los machos pierden peso por apareamiento, por disminución de la actividad de forrajeo, por mala salud, por efectos ambientales como El Niño o por falta de comida. Las hembras pierden peso por desoves, mala salud, efectos ambientales y falta de comida. El mismo comportamiento es observado en iguanas marinas $y$ terrestres en condiciones naturales y en cautiverio (Wikelski, 2000; Márquez, datos no publicados).

\section{Conclusiones}

- Los machos de A. a. son más grandes que las hembras en todas las regiones corporales medidas.

- Ningún macho adulto o subadulto se puede acercar a menos de $2 \mathrm{~m}$ de distancia al territorio de otro macho, pero si permite el ingreso de juveniles $\mathrm{y}$ hembras.

- Las hembras alcanzan la madurez sexual entre los 4-6 meses; cuando han logrado una talla $>52 \mathrm{~mm}$ en LHA. Los machos logran la madurez sexual entre los 5-7 meses; cuando han alcanzado una talla $>55 \mathrm{~mm}$ en LHA.

- Los machos juveniles presentan tasas de crecimiento de $0.23 \mathrm{~mm} /$ día y las hembras 0.11 $\mathrm{mm} /$ día, superior a la de las hembras y machos adultos.

- Los machos se reclutan en mayor número y superviven más que las hembras.

- Luego de un desove, las hembras por debajo de los $59 \mathrm{~mm}$ de LHA, recuperan el peso en poco tiempo; arriba de esa talla, el peso lo superan en forma gradual. Los machos, por debajo de los $69 \mathrm{~mm}$ en LHA, la pérdida de peso es recuperada en poco tiempo; arriba de los $69 \mathrm{~mm}$ de LHA, el peso lo superan en forma lenta.

\section{Agradecimientos}

Nuestra sincera gratitud a las familias Robinson y Porras por permitir vivir y realizar todo el estudio en sus propiedades, a Lady y Jefferson Márquez por su ayuda en la toma de los datos en el campo. A William Eberhard, Julieta Carranza, y a cada una de las personas que ayudaron en la corrección de este documento, y de una $\mathrm{u}$ otra manera a terminar esta investigación. A Omar Achi por la elaboración de los dibujos.

\section{Literatura citada}

Andrews R.M. 1971. Structural habitat and time budget of a tropical Anolis lizard. Ecology 52: 262-270.

Andrews R.M. \& Rand A.S. 1990. Reproducción estacional y fluctuaciones poblacionales a largo plazo de la lagartija Anolis limifrons. pp. 469-476. En: Leigh E. G., Jr., A.S.

Rand \& D. M. Windsor (Eds). Ecología de un bosque tropical, ciclos estacionales y Cambios a largo plazo. Editorial Presencia Ltda. Colombia.

Beuttell K. \& Losos J.B. 1999. Ecological morphology of Caribbean anoles. Herpetol. Monogr. 13:1-28.

Birt R.A., Powell R. \& Greene B.D. 2001. Natural History of Anolis barkeri: a semiaquatic lizard from southern Mexico. J. Herpetol. 35:161-166.

Campbell H. W. 1973. Ecological observations on Anolis lionotus and Anolis poecilopus (Reptilia, Sauria) in Panamá. Am. Mus. Nat. Hist. Univ. Florida. 2516 N.Y.

Carothers J.H. 1984. Sexual selection and sexual dimorphism in some herbivorous lizards. Am. Natur. 124: $244-254$. 
Crews D. 1973. Condition-induced inhibition of sexual receptivity in female lizards (Anolis carolinensis) Physiology and Behavior. 11: 463-468.

Darwin C. 1871. The descent of man and selection in relation to sex. Murray, London. 2

Duelman W.E. 1978. The Biology of an Equatorial Herpeto-fauna in Amazonian Ecuador.

Publ. Mus. Nat. Hist. Univ. Kansas. 65:1-352.

Fitch H.S. 1970. Reproductive Cycles of lizards and snakes. Publ. Mus. Nat. Hist. Univ. Kansas. 52: 1-247.

Fitch H.S. 1981. Sexual size difference in reptiles. Misc. Pbl. Mus. Nat. Hist. Univ. Kansas. 70: 1-72.

Frost D.R. \& Etheridge R. 1989. A Phylogenetic Análisis and Taxonomy of Iguanian Lizards

(Reptilia:Squamata). Misc. Pbl. Mus. Nat. Hist. Univ. Kansas. 81: 1-65.

Gibbons J.W. \&. Lovich J.E. 1990. Sexual dimorphism in turtles with emphasis on the slider turtle (Trachemys scripta). Herpet. Monogra. 4: 1-29.

Gómez L.D. 1986. Vegetación de Costa Rica. Editorial Universidad Estatal a Distancia. San José, Costa Rica.

Guyer C. \& Savage J.M. 1986. Cladistic relationships among Anoles (Sauria: Iguanidae). Syst. Zool. 35: 509531.

Hertz P.E. 1975. Thermal passivity of tropical forest lizard Anolis polylepis. J. Herp. 8: 23-327.

Herrera W. 1985. Clima de Costa Rica. Editorial Universidad Estatal a Distancia. San José, Costa Rica.

Irschick D.J. 1999. Comparative three-dimensional kinematics of the hindlimb for high-speed bipedal and quadrupedal locomotion of lizards. J. Exp. Biol. 202: $1047-1065$

Leal M. \& Losos J.B. 2000. Behavior and Ecology of the Cuban "chipojos bobos" Chamaleolis barbatus and $C$. porcus. J. Herpetol. 34: 318-322.

Leal M., Knox A.K. \& Losos J.B. 2002. Lack convergence in aquatic Anolis lizard. Evolution. 56(4): 785-991.

Losos J.B., Mouton P.N.L.F., Bickel R., Cornelius I. \& Ruddock LL. 2002. The effect of Body armature on escape behavior in cordylid lizards. Anim.. Behav. In. Press.

Price T.D. 1984. The evolution of sexual size dimorphism in Darwin's finches. Am. Natur.123: 500-518.

Ralls K. 1976. Mammals in which females are larger than males. Quart. Rev. Biol. 51: 245-276.

Rand A.S. 1967. Ecology and social organization in the iguana lizard Anolis lineatopus. Proc. U.S. Nat. Mus. 122: $1-77$.
Rand W.M. \& Rand A.S. 1976. Agonistic behavior in nesting iguanas: a stochastic analysis of dispute settlement dominated by the minimization of energy cost. Z. Tierpsichologie. 40: 279-299.

Romero 1.M. \& Wikelski M. 2001. Corticosterone levels predict survival probabilities of Galápagos marine iguanas during El Niño events. PNAS. 98: 7366-7370.

Rueda J.V. 1989. Un nuevo extraordinario saurio de color rojo (Iguanidae:Anolis) para la Cordillera Occidental de Colombia. Trianea (Act. Cient. Tecn., Inderena). 3: 8592.

Savage J.M. \& Villa J. 1986. Herpetofauna de Costa Rica. Society for the study of Amphibians and Reptile. New York.

Savage J.M. \& Guyer C. 1989. Infrageneric classification and species composition of the Anole Genera, Anolis, Ctnonotus, Dactyloa, Norops and Semiurus (Sauria: Iguanidae). Amphibio Reptilia. 10: 105-116.

Selander R.K. \& Giller D.R. 1963. Species limits in the woodpecker genus Centurus (Aves). Bull. Am. Mus. Nat. Hist. 124: 261-271.

Selander R.K. 1972. Sexual selection and dimorphism in birds. Oldine Chicago.

Sexton O.J., Bauman J.\& Ortteb E.P. 1972. Seasonal food habits of Anolis limnifrons. Ecol. 53: 182-186.

Taylor E.H. 1956. A review of the lizards of Costa Rica Univ. Kansas Sci. Bull. 38: 1-322.

Valerio C.E. 1991. La diversidad biológica de Costa Rica. Editorial Heliconia. Fundación Neotrópica, San José, Costa Rica.

Bitt L.J., Zani P.A. \& Durtsche R.D. 1995. Ecology of the lizard Norops oxylophus (Polychrotidae) in lowland forest of southeastern Nicaragua. Can. J. Zool. 73:19181927.

Werner D. \& Rey D. 1994. El manejo de la iguana verde. Tomo I: Biología. Instituto Smithsonian. Balboa, Panamá.

Wikelski M. \& Thom C. 2000. Marine iguanas Shrink to survive El Niño. Nature. 403: 37-38.

Williams E.E. 1976. South American Anoles: The species groups. Papeis Avulsos Zool. Paulo. 29: 259-268.

Young, J. Z. 1977. La vida de los vertebrados. Segunda Ed. Ediciones Omega. S.A.

Barcelona España. 660 pp.

Zar, J. H. 1984. Biostatistical analysis. Second Ed. Prentice Hall, Englewood Cliffs, N.J. 718 p.

\footnotetext{
${ }^{1}$ Estación Científica Charles Darwin, Casilla 17013891 Quito, Isla Santa Cruz, Galápagos-Ecuador. Fax: 593-4564-636, Teléfono: 526-146 ó 147. Correo electrónico: Cruz Márquez marquez@ffcdarwin.org.ec / Solanda Rea: solanda@fcdarwin.org.ec

${ }^{2}$ Universidad de Costa Rica, Casilla 2060, San Pedro de Montes De Oca, Costa Rica. Fax: 506-207-4216, Teléfono: 207-4043. Correo electrónico José Manuel Mora: jmmora@biologia.ucr.ac.cr / Federico Bolaños bolanosv@ns.biologia.ucr.ac.cr
} 